\section{Transplantes de microbiota fecal para tratamento da colite pseudomembranosa (1958-2013): prioridade de descoberta e estilos de pensamento na literatura acadêmica}

\author{
Fecal microbiota transplants \\ in the treatment of \\ pseudomembranous colitis \\ (1958-2013): priority of \\ discovery and thought styles \\ in the academic literature
}

\author{
Maurício Roberto Motta Pinto da Luz \\ 'Pesquisador, Instituto Oswaldo Cruz/Fiocruz. \\ Rio de Janeiro - RJ - Brasil \\ orcid.org/0000-0001-9374-3791 \\ mauluz@ioc.fiocruz.br
}

\author{
Ricardo Francisco Waizbort ${ }^{i i}$ \\ ii Pesquisador, Instituto Oswaldo Cruz/Fiocruz. \\ Rio de Janeiro - RJ - Brasil \\ orcid.org/0000-0003-1469-6638 \\ ricw@ioc.fiocruz.br
}

Recebido em 21 maio 2018.

Aprovado em 4 jun. 2019.

http://dx.doi.org/10.1590/S0104-59702020000400009
LUZ, Maurício Roberto Motta Pinto da; WAIZBORT, Ricardo Francisco. Transplantes de microbiota fecal para tratamento da colite pseudomembranosa (1958-2013): prioridade de descoberta e estilos de pensamento na literatura acadêmica. História, Ciências, Saúde Manguinhos, Rio de Janeiro, v.27, n.3, jul.-set. 2020, p.859-878.

Resumo

Em 1958, Eiseman e colaboradores publicaram o primeiro artigo científico relatando o uso de transplante de microbiota fecal para tratar casos graves de colite pseudomembranosa. A relevância desse trabalho inovador só foi reconhecida em 1990. A literatura acadêmica sobre o tema caracteriza-se por sucessivas reconstruções. Sugerimos que tais reconstruções foram orientadas por questões de atribuição de prioridade de descoberta científica nos termos propostos por Merton. A retomada do uso de transplantes de microbiota fecal é interpretada como processo de gênese de um fato científico, conforme Fleck: ocorre a mudança de um estilo de pensamento baseado no uso de antibióticos no tratamento de doenças infecciosas para outro que considera as relações ecológicas entre hospedeiros, vetores e agentes etiológicos de doenças.

Palavras-chave: Clostridium difficile; colite pseudomembranosa; estilos de pensamento; prioridades de descoberta científica.

\section{Abstract}

In 1958, Eiseman and contributors published the first scientific paper reporting the use of fecal microbiota transplant for treating pseudomembranous colitis. The relevance of this innovative paper was only acknowledged in 1990. The academic literature on the theme is characterized by a narrative that has undergone successive revisions. We suggest that such revisions were based on claims of priority of scientific discoveries, as described by Merton. The revival of fecal microbiota transplants is interpreted as a process of genesis of a scientific fact, as defined by Fleck: there is a switch from a thought style based on the use of antibiotics to treat infectious diseases to another that accepts the ecological relations between hosts, vectors and parasites.

Keywords: Clostridium difficile; pseudomembranous colitis; thought style; priority of scientific discoveries. 
$\mathrm{E}$ m 1958, diante de quatro casos graves e recorrentes daquilo que na época era denominado "enterocolite pseudomembranosa" (atualmente designada como colite pseudomembranosa), um grupo de médicos da Escola de Medicina do Colorado, sob a liderança do cirurgião Ben Eiseman, utilizou uma abordagem inovadora por eles designada "enema fecal"1 (Eiseman et al., 1958, p.854). A enterocolite pseudomembranosa estava se tornando uma complicação comum no período pós-operatório de diversas cirurgias, sendo então associada a infecções por Staphilococcus sp. decorrentes do uso de antibióticos. O "enema fecal" consistia na introdução de uma solução diluída de "fezes de um doador sadio" no organismo do paciente por via retal, em associação com terapias de suporte. Segundo os autores, a intervenção se baseava no princípio da recolonização do cólon pela flora intestinal característica de condições não patológicas:

foi feita uma tentativa de restabelecer a flora bacteriana intestinal normal por meio da administração de fezes normais no cólon de pacientes com a doença. Essa terapia baseia-se no fato de que o crescimento estafilocócico excessivo ocorre quando outros organismos desaparecem e que a reintrodução das bactérias, vírus e bacteriófagos normalmente encontrados no cólon pode restabelecer o equilíbrio da natureza, com a subsidência da dominância estafilocócica e dos sintomas angustiantes por ela causados (Eiseman et al., 1958, p.854).

Embora o uso de Lactobacillus sp. obtidos do leite como estratégia de reconstituição da flora intestinal (atualmente denominada de microbiota intestinal) já fosse conhecido, Eiseman e seu grupo não fizeram referência a qualquer estudo anterior sobre o uso de enemas fecais. Isso sugere que essa abordagem era, para eles, nova. Os resultados do uso dos enemas fecais realizados pelo grupo de Eiseman foram muito auspiciosos: "Em cada caso, o curso clínico foi acentuadamente melhorado e o estafilococo ... foi substituído por não patógenos normais do cólon após tal terapia" (Eiseman et al., 1958, p.858). Os quatro pacientes tratados com enemas fecais evoluíram de quadros graves para condições de alta hospitalar em poucos dias. A abordagem mostrou-se promissora, ainda que o número de pacientes fosse pequeno. Os autores explicitaram a expectativa de que novos estudos na mesma linha se seguissem: "Para avaliar cientificamente a eficácia dos enemas fecais seria necessário suspender as demais formas de tratamento dos pacientes, uma alternativa injustificável dada a gravidade da doença ... sugere-se que essa abordagem terapêutica simples, porém racional, deve ser avaliada por meio de estudos clínicos mais extensivos" (Eiseman et al., 1958, p.859).

É importante ressaltar que na época a principal forma de tratamento para a colite pseudomembranosa era o uso de antibióticos. A repercussão ao trabalho original de Eiseman e seus colaboradores (1958) foi mínima: nos 30 anos seguintes, o artigo recebeu apenas três citações em periódicos, duas em 1961 (sem relação com novo uso de enemas) e outra em 1983, em artigo no qual a técnica foi retomada (e do qual trataremos adiante). Eiseman não tornou a ser citado até $1990 .^{2}$

Até 1958, Eiseman já havia publicado mais de cinquenta artigos em periódicos reconhecidos, como The New England Journal of Medicine e Journal of Clinical Investigation. Ao longo de sua carreira, Eiseman publicou mais de trezentos artigos em periódicos. Alguns deles foram citados até dez vezes nos anos subsequentes à sua publicação e receberam 
mais de vinte citações até 1983. Outros artigos de Eiseman também publicados no Surgery receberam diversas citações nos cinco anos subsequentes à publicação. O periódico Surgery continua sendo publicado atualmente e tem fator de impacto considerável $(3,574)$. Tanto o autor quanto o periódico, portanto, eram (e são) reconhecidos pela comunidade acadêmica. Não é razoável supor que a ausência de citações da publicação de 1958 se devesse à pouca visibilidade de qualquer um dos dois.

A expectativa de Eiseman de que os enemas fecais recebessem avaliação clínica extensiva só viria a se concretizar mais de cinquenta anos depois, em 2013, quando Van Nood e colaboradores publicaram o primeiro ensaio randomizado para teste da efetividade dos transplantes de microbiota fecal (TMFs) no tratamento da colite pseudomembranosa, demonstrando que os TMFs são eficazes e seguros (Van Nood et al., 2013). A colite pseudomembranosa é considerada hoje uma epidemia e vem afetando cada vez mais pacientes hospitalares, tornando-se uma doença progressivamente mais refratária a antibióticos. O tratamento com algum tipo de TMF é compreendido como uma das poucas alternativas para o problema.

Reconhecemos que diversos fatores que não exploraremos aqui devem ter contribuído para a pouca utilização dos TMFs após o trabalho de Eiseman e seus colaboradores (1958). Entre eles, podemos mencionar os riscos de transmissão de outros patógenos pelos enemas fecais (Seal et al., 1987; Finnegold, George, 1988) e a repulsa dos seres humanos por suas próprias secreções e excreções conhecida como yuck factor (Curtius, Biran, 2001). O presente trabalho tem dois objetivos específicos complementares. Evidenciaremos como a narrativa predominante na literatura acadêmica sobre a cronologia de utilização dos TMFs, embora seja apresentada de modo linear, teve um processo de construção caracterizado por sucessivas reconstruções. Sugerimos que tais reconstruções foram orientadas por questões relacionadas à atribuição de prioridade acerca de uma descoberta científica, nos termos propostos originalmente pelo sociólogo da ciência Robert Merton (1957). A atribuição da prioridade de descoberta no uso do TMF parece se resolver em 1990, mas o tema é retomado em tempos mais recentes para engendrar outras narrativas que envolvem novos atores de diversas nacionalidades.

Além disso, procuraremos compreender o uso do TMF, a partir da década de 1980, como a origem de um fato científico que revela uma mudança de estilo de pensamento (Fleck, 2010): de um pensamento centrado em antibióticos, como "balas mágicas" para erradicar doenças infecciosas (Anderson, 2004; Farley, 2004; Garret, 1995), para um estilo de pensamento que considerava toda uma rede de relações ecológicas entre hospedeiros e agentes etiológicos de doenças (Anderson, 2004).

Merton (1957) discute possíveis causas de as disputas de prioridade serem tão recorrentes na história da ciência. Depois de descartar as hipóteses que apontam para a natureza humana (todos os indivíduos humanos são naturalmente competitivos) ou para o egocentrismo de alguns homens de ciência, ele analisa com cuidado e muitos exemplos a hipótese de que tais disputas seriam decorrentes das normas institucionais da ciência. Como instituição, a ciência valoriza a descoberta de novidades, que implicam impactos sociais e científicos, e, associado a essas descobertas, há um sistema de recompensas. Segundo Merton, os cientistas originariamente envolvidos no processo de descobertas adquirem reputação e 
reconhecimento, que podem se manifestar sob a forma de epinômios, prêmios, recursos para pesquisa, convites para conferências e palestras, atração de outros indivíduos talentosos dispostos a trabalhar com os descobridores originais, entre outras vantagens:

Dada a importância institucional de gratidão e da estima como o único direito de propriedade do cientista sobre seus descobrimentos, o interesse pela prioridade científica é uma reação 'normal'. As controvérsias sobre prioridade que marcam a história da ciência moderna são produto da importância institucional concedida à originalidade. Surge uma cooperação competitiva. Os resultados da competição são comunizados e a estima cresce para o produtor. As nações alegam direitos à prioridade e as novas entradas na comunidade da ciência são rotuladas com os nomes dos nacionais (Merton, 1970, p.658).

Merton (1957, p.655) ressalta, após apresentar e analisar várias formas de estabelecer prioridade na história das ciências, o lugar do artigo científico: "para a maioria de nós, artesãos da pesquisa, imprimir coisas torna-se um equivalente simbólico da realização de descobertas significativas". Seguindo esse raciocínio, utilizaremos como fontes de pesquisa os artigos publicados em periódicos científicos a partir de 1958, data do trabalho de Eiseman e seus colaboradores. Tais textos descrevem estudos sobre o uso clínico ou experimental dos TMFs para tratamento de agravos gastrointestinais. Exploraremos ainda os artigos de revisão publicados após a retomada dos estudos com TMFs, considerando que seria impossível investigar as centenas de estudos empíricos publicados nos últimos vinte anos (Bojanova, Bordenstein, 2016). Além disso, artigos de revisão em geral se detêm mais em aspectos históricos do que os estudos empíricos. Em ambos os casos, focalizaremos especialmente as citações bibliográficas em seus respectivos contextos, com o objetivo de demonstrar que elas fornecem indícios para compreender a importância dos processos de atribuição de prioridade na estruturação da narrativa sobre os TMFs. Portanto, nossas hipóteses explicativas se basearão com exclusividade naquilo que pode ser inferido a partir dos conteúdos dessas fontes. Vale destacar ainda que utilizaremos as citações bibliográficas estritamente como indicações das fontes utilizadas preferencialmente pelos diversos autores, sem intenção de inferir, de forma implícita ou explícita, qualquer mérito científico sobre os trabalhos citados ou omitidos por eles.

Ao longo da análise da construção da narrativa acerca da prioridade, identificamos a origem e o desenvolvimento de um fato científico: o uso dos transplantes de microbiota fecal como tratamento para a colite pseudomembranosa. O estabelecimento desse fato se deveu a toda uma série de cientistas que compartilharam um modo específico de pensar e agir em relação à doença. Apoiamo-nos nos conceitos de Ludwik Fleck de "fato científico" e "estilo de pensamento". Logo no prefácio de seu clássico Gênese e desenvolvimento de um fato científico - publicado inicialmente em 1935 -, Fleck (2010, p.37) pergunta: "O que é um fato?". Não define o que seria um fato, ou mesmo um fato científico, nesse prefácio, mas afirma que "um fato da medicina" seria especialmente útil para os seus fins históricos e epistemológicos: no caso, "o fato de a chamada reação de Wassermann ser relacionada com a sífilis" (p.38).

Segundo Condé (2018, p.169), Fleck procura mostrar que o fato científico não é algo simplesmente dado, mas algo que, "para além de uma descrição do empírico, se estabelece e se desenvolve ... através de um complexo processo de interações sociais e empíricas ao 
longo de muito tempo". No decorrer do livro, Fleck (2010, p.82) mostra como essa realização, o fato científico, é o produto de uma tradição ou comunidade científica que ele chama de coletivo de pensamento, que por sua vez se relaciona com um estilo de pensamento: "Se definirmos o 'coletivo de pensamento' como a comunidade das pessoas que trocam pensamentos ou se encontram em uma situação de influência recíproca de pensamento, temos, em cada uma dessas pessoas, um portador do desenvolvimento histórico de uma área de pensamento, de um determinado estado do saber e da cultura, ou seja, um estilo específico de pensamento".

Iremos nos basear mais especificamente no conceito de estilo de pensamento e suas relações com a origem e a história do uso dos TMFs para tratar a colite pseudomembranosa. Para Fleck (2010, p.94), o estilo de pensamento "consiste numa determinada atmosfera e sua realização":

Podemos ... definir o estilo de pensamento como percepção direcionada em conjunção com o processamento correspondente no plano mental e objetivo. Esse estilo é marcado por características comuns dos problemas, que interessam a um coletivo de pensamento; dos julgamentos que considera como evidentes e dos métodos que aplica como meios do conhecimento. É acompanhado, eventualmente, por um estilo técnico e literário do sistema do saber (Fleck, 2010, p.149).

Como veremos, a "atmosfera" que promoveu o uso dos TMFs para tratamento da colite pseudomembranosa, e que o tornou um fato científico, é diferente do estilo que preconiza o uso de antibióticos para tentar debelar a doença.

Na seção seguinte, apresentaremos os conceitos biomédicos fundamentais subjacentes à colite pseudomembranosa. Eles serão essenciais para compreender o funcionamento dos TMFs e, consequentemente, a cronologia de sua utilização no tratamento dessa doença. Em seguida descreveremos o processo de construção da narrativa sobre o uso dos TMFs ao longo dos últimos sessenta anos. Essa descrição será objeto das análises nas quais pretendemos avançar em direção aos dois objetivos propostos.

\section{A biologia do Clostridium difficile e a colite pseudomembranosa}

Hoje se reconhece que a colite pseudomembranosa descrita por Eiseman tem como agente etiológico o Clostridium difficile. Essa relação causal foi estabelecida somente em 1977 (Bartlet et al., 1977), muito posteriormente à descrição original da colite pseudomembranosa, que, segundo Bartlet (1979), data do final do século XIX.

O Clostridium difficile é uma espécie de Eubactéria da divisão (filo) Firmicutes, grampositivas, que se reproduz por intermédio de esporos, encontrado em baixa frequência na microbiota de $2 \%$ a $5 \%$ da população de adultos saudáveis (Ghose, 2013). Sua presença em cerca de $60 \%$ a $70 \%$ dos recém-nascidos e a relativa ausência em adultos assintomáticos sugere que a espécie é eliminada na competição com os demais componentes da microbiota (Ghose, 2013; Ley, Peterson, Gordon, 2006).

O trato gastrointestinal em condições normais é habitado por cerca de 100 trilhões de microrganismos pertencentes a milhares de espécies diferentes de bactérias, fungos e vírus, 
conhecidos coletivamente como microbiota intestinal. A maior parte dessa microbiota reside no cólon (Ley, Peterson, Gordon, 2006; Whitman, Coleman, Wiebe, 1998). O uso de substâncias antibióticas contribui para uma redução drástica da biomassa e da diversidade dessa microbiota. A colite pseudomembranosa é uma infecção que se produz quando o Clostridium difficile coloniza de forma massiva o cólon de indivíduos submetidos a um uso prévio de antibióticos que empobreceu a microbiota do hospedeiro (Rupnik, Wilcox, Gerding, 2009, p.527). A colite pseudomembranosa decorre da ação de duas principais toxinas produzidas pelo patógeno, levando ao aparecimento de placas esbranquiçadas denominadas pseudomembranas (Gore et al., 2015, p.242). Seu quadro clínico varia desde casos assintomáticos até outros de diarreias graves, com consequente sepse que, frequentemente, leva pacientes hospitalizados à morte (Ganc et al., 2015). A importância desse agravo para a saúde pública decorre de sua incidência crescente, associada a um aumento de sua morbidade e ao surgimento de cepas de Clostridium difficile mais virulentas e com maior resistência aos antibióticos.

A título de exemplo, um estudo realizado em 2013 mostrou como, na história recente (2000-2013), o Clostridium difficile foi associado a uma alarmante taxa de 337 mil infecções e 14 mil mortes por ano, merecendo atenção urgente da saúde pública para tentativas de limitar a transmissão. Despesas nosocomiais para o manejo de infecções envolvendo Clostridium difficile foram estimadas em até US\$ 4,8 bilhões por ano nos EUA (Galdys, Curry, Harrison, 2014, p.967-968). O aumento da incidência e da morbidade das infecções causadas por Clostridium difficile, propiciado pela utilização de antibióticos, ocorreu ao longo das últimas décadas quase simultaneamente à compreensão biológica desse agravo, justo quando o uso dos TMFs experimentou uma retomada também crescente.

\section{A retomada do uso dos TMFs no tratamento da colite pseudomembranosa}

A identificação do Clostridium difficile como agente etiológico da colite pseudomembranosa (Bartlet et al., 1977) contribuiu para a publicação de novos estudos de caso reportando a utilização dos TMFs nos anos imediatamente posteriores. Essa retomada se intensificou ao longo das décadas seguintes, culminando na publicação do primeiro ensaio clínico sobre seu uso (Van Nood et al., 2013). Ao longo desse período, estabeleceu-se uma narrativa na literatura acadêmica na qual é apresentada uma espécie de cronologia da utilização dos TMFs. Essa narrativa, com algumas variações, consolidou-se desde então nos artigos acadêmicos para descrever a prioridade da descoberta do uso desse tipo heterodoxo de transplante. Apresentamos a seguir dois exemplos de narrativas do tipo. A primeira delas é encontrada nos parágrafos iniciais na introdução de artigo publicado por Aroniadis e Brandt (2013, p.1080):

A administração oral de suspensões de fezes humanas em pacientes com quadros de envenenamento ou diarreia grave foi descrita pela primeira vez no século IV, na China, por Ge Hong (Zhang et al., 2012). No século XVI, Li Shizen descreveu o uso de uma variedade de preparações à base de fezes humanas para o tratamento de diarreias, febre, dor, vômitos e constipação (Zhang et al., 2012). No século XVII, TMFs foram 
usados na medicina veterinária e denominados transfaunação (Borody et al., 2004). O primeiro uso de enemas fecais para o tratamento de colite pseudomembranosa foi relatado em 1958 por Eiseman et al.

Van Nood e colaboradores (2014) também propõem uma cronologia análoga, porém omitem a transfaunação e agregam um novo elemento: o uso de fezes de camelo no tratamento de diarreias em meados do século XX.

O consumo de fezes de camelo frescas e quentes foi recomendado pelos beduínos como um remédio para a disenteria bacteriana; sua eficácia foi confirmada por soldados alemães na África durante a Segunda Guerra Mundial. Na literatura médica moderna, a infusão de fezes de doadores saudáveis foi relatada pela primeira vez em 1958, quando o cirurgião Eiseman descreveu uma resposta heroica em pacientes com diarreia associada a antibióticos, que foram tratados com enemas contendo fezes de doadores (Van Nood et al., 2014, p.34).

Como iremos mostrar, entre os estudos citados, o primeiro autor a ter sua prioridade reconhecida foi Eiseman. Já as referências à transfaunação, à medicina tradicional chinesa e à utilização de fezes de camelo foram incorporadas mais tarde. E mesmo esse reconhecimento da prioridade de Eiseman não se deu de imediato na retomada do uso dos enemas fecais a partir de princípios da década de 1980, e sim cerca de uma década mais tarde.

Considerando as publicações em periódicos científicos, podemos situar a retomada do uso de TMFs em 1981, quando Wilson e colaboradores testaram a hipótese de que a flora intestinal normal seria capaz de suprimir o crescimento de Clostridium difficile em hamsters, que eram então o único modelo experimental da colite pseudomembranosa: "Devido à associação da colite induzida por $C$. difficile com o uso de antibióticos, foi sugerido que os componentes da flora normal do cólon suprimem a população de $C$. difficile e que os antibióticos alteram a flora colônica, liberando C. difficile dessa inibição. Usando o modelo dos hamsters, testamos essa hipótese" (Wilson, Silva, Feket, 1981, p.626).

O grupo de Wilson parece ter recorrido aos enemas fecais obtidos de animais normais apenas como uma técnica para transferir amostras de flora intestinal entre animais. Eles não mencionaram ao longo de todo o texto qualquer perspectiva de sua utilização no tratamento de seres humanos. Aparentemente, eles a utilizaram para testar e corroborar sua hipótese sobre a gênese da infecção pelo Clostridium difficile: "Nossos resultados apoiam a hipótese de que a flora cecal normal de hamsters suprime a população de C. difficile in vivo. A administração de homogenados cecais levou a uma diminuição significativa no número de C. difficile" (Wilson, Silva, Feket, 1981, p.627).

Implicitamente, os autores sugerem que há uma competição, conceito ecológico importante, entre as populações do patógeno e os organismos da flora cecal normal. Em termos gerais, portanto, Wilson e seu grupo formularam uma hipótese e utilizaram uma metodologia com conceitos subjacentes similares aos de Eiseman, aplicando-os a um modelo animal. Eles o fizeram, no entanto, sem citar o estudo de Eiseman et al. (1958). É possível, contudo, supor que Wilson e seu grupo o desconhecessem.

No mesmo ano, Bowden, Mansberger e Lykins (1981) publicariam um relato do uso de enemas fecais em humanos para o tratamento de casos graves e recorrentes de colite 
pseudomembranosa. É notável que, embora tenha sido publicado em 1981, o estudo relatava enemas fecais realizados em pacientes desde 1970. Bowden e seu grupo afirmavam que "em medicina veterinária é comum tratar cavalos acometidos por diarreia com soluções diluídas de fezes de animais normais administradas oralmente por meio de um tubo" (Bowden, Mansberger, Lykins, 1981, p.178). Além dessa menção a abordagens veterinárias similares aos enemas fecais, Bowden e seu grupo efetivamente citavam o estudo de Eiseman. Mas é interessante notar o contexto dessa citação: o trabalho de Eiseman é mencionado na introdução do artigo, como parte de uma situação na qual a colite pseudomembranosa ainda era associada de maneira equivocada ao crescimento excessivo de Staphylococcus aureus e não à infecção por Clostridium difficile: "Eiseman et al. também demonstraram crescimento expressivo de Staphylococcus e notaram uma melhora acentuada no curso clínico de quatro pacientes quando os enemas fecais foram administrados" (p.178).

A citação nesse contexto posiciona o trabalho de Eiseman de tal modo que não lhe confere prioridade na descoberta dos TMFs, mas apenas se refere a ele como um estudo prévio que evidenciava o crescimento excessivo de $S$. aureus em pacientes com colite pseudomembranosa. Essa percepção da citação de Eiseman em contexto periférico é reforçada quando Bowden, Mansberger e Lykins (1981, p.178) descrevem o raciocínio subjacente ao uso de enemas fecais: "Sempre argumentamos que o supercrescimento bacteriano era o denominador etiológico comum (referindo-se à colite pseudomembranosa). Nossa abordagem terapêutica baseou-se no conceito de que se a restauração da homeostase da flora fecal pudesse ser realizada, a doença se resolveria".

Embora seja notável a semelhança entre esse delineamento e as ideias centrais de Eiseman ("reestabelecer a flora bacteriana intestinal normal"), a utilização do pronome "nossa", bem como a ausência de quaisquer referências ao procedimento descrito em 1958, é sugestiva do não reconhecimento da prioridade de Eiseman sobre o uso e os princípios subjacentes aos enemas fecais. O fato de que essas mesmas ideias são reapresentadas na discussão com alterações menores na redação corrobora essa intepretação. E, sobretudo, para nossa abordagem, os autores destacam o caráter inovador de detalhes da própria técnica utilizada por eles: "O uso de tubos longos para infundir a suspensão fecal próxima de uma linha de sutura recente não foi relatada anteriormente na literatura" (Bowden, Mansberger, Lykins, 1981, p.183), embora os princípios subjacentes a essa técnica fossem rigorosamente os mesmos de Eiseman. É possível supor que a citação ao trabalho de Eiseman e colaboradores (1958) em um contexto distinto (e periférico) tenha contribuído para que esse trabalho tivesse pouca visibilidade depois.

Note-se que essa é uma interpretação que leva em conta a importância dada às citações na ciência. Em artigo publicado em 1988, Merton aponta para duas funções da citação: a função cognitiva instrumental, que auxilia cientistas e acadêmicos a verificar enunciados ou dados no texto citado ou a recuperar informações; e a função simbólica, que "mantêm tradições intelectuais e proporcionam o reconhecimento dos pares requerido para o efetivo trabalho da ciência como atividade social" (Merton, 1988, p.621). E, como enfatizado por Merton (1957), a publicação de trabalhos científicos é uma forma importante de alegação de prioridade sobre uma descoberta ou inovação. Os cientistas cuja prioridade de descoberta é reconhecida estão em posição de destaque para receber as vantagens 
concedidas pelo sistema de recompensas típico da ciência, que premia a precocidade na formação do cientista e o grupo que primeiro alcança uma descoberta importante (Merton, 1988; Strevens, 2003).

Em um estudo de caso publicado dois anos depois do trabalho de Bowden e colaboradores, Schwan e colaboradores (1983) relataram o uso bem-sucedido de enemas fecais para tratamento de uma paciente com colite pseudomembranosa. Como não há citações bibliográficas naquela publicação, não é possível afirmar se naquele momento o grupo de Schwan conhecia ou não os artigos dos grupos de Bowden e de Eiseman. No entanto, um novo artigo publicado no ano seguinte por Schwan e colaboradores (1984) parece esclarecer essa dúvida. Ao relatarem novo uso bem-sucedido de enema fecal no tratamento da infecção por Clostridium difficile, citam diversas referências bibliográficas, mas não há menção ao trabalho de Eiseman ou de Bowden. Schwan, porém, mostra conhecer o trabalho de Wilson, Silva e Feket (1981): “Além disso, a administração de homogenatos cecais foi relatada para diminuir o número de $C$. difficile e prevenir a infecção do ceco em hamsters. Os homogenatos foram administrados oralmente e por infusão retal [citação a Wilson, Silva, Feket, 1981]" (Schwan et al., 1984, p.213).

Perceba-se que esses autores se referem à "substituição" de flora, fundamento central dos TMFs, sem mencionar Eiseman. Ainda se referiram a relatos pessoais (no sentido de não publicados) sobre o uso ineficaz de enemas fecais para tratamentos de infecções por espécies patogênicas de bactérias do gênero Salmonella sp: "A flora intestinal normal também foi transferida em tentativas, embora infrutíferas, de erradicar Salmonella em portadores crônicos, dando aos pacientes enemas preparados a partir de fezes normais" (Schwan et al., 1984, p.213). É possível especular que o conhecimento informal circulante em meios médicos acerca dos enemas fecais tenha surgido em decorrência do trabalho de Eiseman, ainda que o artigo propriamente dito tenha permanecido na periferia do cenário acadêmico.

Parece-nos, portanto, razoável concluir que, na percepção do grupo de Anna Schwan, seus próprios artigos seriam os primeiros relatos formais do uso de enemas fecais como estratégias para tratamento em humanos. A técnica teria sido inspirada, para Schwan e colaboradores, tanto em experiências anteriores bem-sucedidas em animais quanto em metodologias distintas, porém baseadas nos mesmos princípios, utilizadas em humanos. Embora mencionem comunicações pessoais como fontes de outros usos de enemas fecais, isso posiciona o próprio trabalho como o primeiro artigo descrevendo a utilização de um TMF.

Essa interpretação é corroborada pelo fato de que, a partir de então, os poucos estudos adicionais publicados na época sobre o uso de TMF posicionam Bowden e Schwan como precursores. Este é o caso, por exemplo, do trabalho do grupo do microbiologista Borriello (Seal et al., 1987), um dos principais estudiosos das relações entre microbiota intestinal e Clostridium difficile. Na introdução do artigo, eles descrevem as terapias alternativas utilizadas até então no tratamento de infecções por Clostridium difficile, incluindo os enemas fecais e ponderando sobre seus riscos. Mas o fazem citando apenas Bowden e Schwan:

Wilson et al. demonstraram que infecções do ceco podem ser prevenidas em hamsters tratados com antibióticos, dando-lhes flora cecal normal por uma combinação das vias oral e retal, e Bowden et al. e Schwan et al. utilizaram com sucesso enemas fecais para tratar humanos. Existe, obviamente, alguma preocupação em dar aos pacientes 
uma flora complexa, mista e indefinida, que pode conter potenciais patógenos (Seal et al., 1987, p.51).

Deve estar claro, a essa altura, que os TMFs eram e são utilizados como alternativas ao uso de antibióticos. Isso é fundamental para compreender, como se verá adiante, que há pelo menos duas formas diferentes de tratar a colite pseudomembranosa e elas estão relacionadas cada qual com um estilo de pensamento distinto.

Uma fonte adicional valiosa de informações para compreensão das alegações de prioridade de descoberta sobre o uso dos TMFs foi publicada em 1988: Clostridium difficile: seu papel nas doenças intestinais, livro multidisciplinar ambicioso, inteiramente dedicado ao agente causador da colite pseudomembranosa, para o qual contribuíram alguns dos principais pesquisadores no campo. O uso de enemas fecais não passou despercebido de tantos autores importantes: há referências explícitas a eles em dois capítulos - mas elas são distintas. Kenneth Wilson, responsável pelo capítulo de ecologia microbiológica, líder do grupo de autores do primeiro relato do uso de enemas fecais em hamsters, além de autorreferência, cita apenas o artigo de Schwan e colaboradores (1984): "No modelo de hamster ... homogenados preparados anaerobicamente de conteúdos fecais ... suprimem a colonização por linhagens de Clostridium diffcile ... Uma abordagem semelhante em humanos tem se mostrado promissora [referindo-se ao trabalho de Schwan e colaboradores 1984]" (Wilson, 1988, p.184).

Já Finnegold e George (1988), autores do capítulo sobre terapias, além de mencionar os trabalhos de Wilson em modelos animais, citaram exclusivamente o relato de Bowden e colaboradores: "Resultados favoráveis foram obtidos em 13 de 16 pacientes com colite pseudomembranosa usando enemas de fezes obtidas de residentes cirúrgicos [citação de Bowden]. O risco desse procedimento, é claro, é a possibilidade de transferência de agentes infecciosos ou oncogênicos por meio dos enemas fecais (Finnegold, George, 1988, p.353).

Rial Rolfe, organizador do livro e autor do capítulo "Colonização assintomática do intestino por Clostridium difficile", tampouco citou o trabalho de Eiseman e colaboradores (1958) naquele momento. O fato de que Rolfe viria a citar Eiseman em um artigo de revisão em 1996 sugere que ele o desconhecia em 1988. Finalmente, a utilização de estratégias de recolonização do cólon pela flora normal recebe destaque na seção de conclusões: "A interferência bacteriana como meio de tratamento da doença intestinal associada a C. difficile é um caminho estimulante para futuras experimentações" (Rolfe, Finnegold, 1988, p.390).

Não havia, portanto, em um livro dedicado ao tema da colite pseudomembranosa sob diversos pontos de vista nos quais ela seria pertinente, qualquer referência ao trabalho de Eiseman e colaboradores (1958). Isso indica que ele permanecia em relativa obscuridade, ao contrário dos estudos de Bowden, Mansberger e Lykins (1981) e Schwan e colaboradores (1984).

O uso de procedimentos análogos ao enema fecal foi relatado por Tvede e Madsen (1989) como tratamento bem-sucedido para outra enfermidade, a colite ulcerativa, em apenas sete pacientes. O procedimento foi bem-sucedido na resolução dos sintomas e, portanto, na aparente cura da colite ulcerativa. Tvede e Madsen citaram os trabalhos de Bowden, Mansberger e Lykins (1981) e o segundo artigo de Schwan e colaboradores (1984): "Outras abordagens para o tratamento da diarreia recorrente devido a Clostridium difficile incluem ... 
a substituição da microflora intestinal normal por infusão retal de fezes homólogas" [citação Bowden, Mansberger, Lykins, 1981; Schwan et al., 1984] (Tvede, Madsen, 1989, p.1156).

De certo modo, a citação a ambos os estudos como predecessores no uso dos TMFs não altera a prioridade de descoberta atribuída implicitamente a Bowden, Mansberger e Lykins (1981). Isso porque, além de não citarem Eiseman e colaboradores (1958), de acordo com as datas de publicação dos dois estudos, a precedência caberia ao trabalho de Bowden, Mansberger e Lykins, publicado em 1981. Que na época os autores não mencionassem trabalhos recentes ou contemporâneos aos seus, seria compreensível, dado o longo tempo que decorria entre a submissão do manuscrito, sua publicação e ampla disponibilização por meio de cópias impressas. No entanto, as repetidas omissões do estudo seminal de Eiseman e colaboradores (1958) em anos muito posteriores sugerem que ele era desconhecido pela maior parte dos autores na década de 1980. Outra hipótese, senão alternativa, pelo menos complementar, baseia-se no fato de que, embora o estudo de Eiseman tenha sido citado por Bowden, Mansberger e Lykins (1981), ele foi associado à atribuição equivocada ao Staphylococcus como agente etiológico da colite pseudomembranosa. Como vimos, esse papel já havia sido atribuído de forma definitiva ao Clostridium difficile em 1977 (Bartlett, 1977). Essa associação do trabalho de Eiseman com um agente etiológico distinto pode ter dificultado o reconhecimento da prioridade de sua descoberta.

Finalmente, em 1990, Borriello publicou uma extensiva revisão sobre as relações entre o Clostridium difficile e a flora intestinal. Naquele artigo, pela primeira vez era atribuída a Eiseman e colaboradores a prioridade da descoberta do uso dos enemas fecais para recolonização do trato gastrointestinal humano. Borriello, porém, o fazia ainda na perspectiva da associação entre a doença e os Staphylococcus aureus. É importante destacar, no entanto, que Borriello foi parcimonioso também ao apresentar os dados de Bowden, ponderando que a infecção por Clostridium difficile havia sido claramente estabelecida em apenas um dos 21 pacientes daquele estudo:

No final dos anos 1950, quando a colite pseudomembranosa estafilocócica estava se tornando um problema ... Eiseman notou uma melhora acentuada em quatro pacientes após a administração de enemas fecais. Bowden e colegas trataram 16 pacientes com colite pseudomembranosa ... Destes, apenas um foi suficientemente recente para ter sido examinado para a citotoxina de $C$. difficile com resultado positivo. No total, 21 pacientes foram tratados desde então e 18 deles, incluindo o paciente positivo para a citotoxina de $C$. difficile, apresentaram melhora dramática ... sendo o caso mais bem documentado aquele reportado por Schwan e colaboradores (Borriello, 1990, p.64).

A atribuição da prioridade de descoberta ao trabalho original de Eiseman e colaboradores (1958) foi, portanto, tardia e parcial. Pode-se apenas especular sobre as razões dessa atribuição por parte de Borriello (1990). É possível que a relevância adquirida pelos TMFs como alternativas clínicas diante do recrudescimento da morbidade da colite pseudomembranosa, causada precipuamente pelo uso de antibióticos, tenha levado Borriello a examinar de maneira mais criteriosa os relatos de uso daquela abordagem. Isso o levaria a reconhecer que tanto os pacientes de Bowden quanto os quatro pacientes de Eiseman correspondiam efetivamente a casos de colite pseudomembranosa. Embora Borriello (1990) ainda utilizasse a expressão diarreia estafilocócica em relação ao estudo de Eiseman, talvez 
para se ater ao termo utilizado na época pelos autores, ele de fato reconhece sua prioridade na descoberta do uso dos TMFs no tratamento da colite pseudomembranosa.

A partir de 1990, a narrativa sobre o uso dos TMFs no tratamento das infecções por Clostridium difficile se altera de forma completa e definitiva: os novos estudos passam a citar Eiseman e pelo menos mais um dos três artigos publicados na década de 1980. Em revisões sobre terapias baseadas em probióticos, Fuller (1991) cita Eiseman, Bowden e o segundo artigo de Schwan e colaboradores (1984), enquanto Roffe (1996) cita essas três fontes e o primeiro artigo de Schwan e colaboradores (1983).

Curiosamente, mesmo após o reposicionamento do relato de Eiseman por Borriello (1990), persiste certo desajuste sobre sua importância em alguns artigos que o incluíam na sequência de estudos articulados em uma cronologia linear. Esse é o caso da revisão publicada por Persky e Brandt (2000, p.3284) quando afirmavam que: "À época [referindose a 1958], acreditava-se que a administração de fezes frescas inibiria a proliferação de $S$. aureus ... Mais tarde, Bowden e colaboradores testaram esta hipótese em 16 pacientes com colite pseudomembranosa".

Para Persky e Brandt (2000), a hipótese proposta pelo grupo de Eiseman aparece como sendo testada pela equipe de Bowden. Porém, como já vimos, o próprio Eiseman interpretava explicitamente seus resultados como uma recolonização do trato intestinal pelos organismos presentes nos enemas fecais. Isso sugere que a prioridade implicitamente atribuída ao trabalho de Bowden, Mansberger e Lykin (1981) ainda persistia. Parece-nos razoável especular, por exemplo, que com o reconhecimento da relevância das pesquisas com TMFs em princípios da década de 1980, a prioridade de sua descoberta tenha se tornado relevante para o sistema de recompensas da ciência. Segundo Dasgupta e David (1994), a tendência de a ciência premiar a prioridade de descoberta, em detrimento de outras formas de distribuição de recursos, deve-se ao menos em parte à facilidade de mensuração da prioridade em termos de data de publicação. Isso reforça a importância dos papers, conforme pontuado por Merton (1957). Esse sistema de reconhecimento acelera não só a publicação dos resultados obtidos como o próprio processo de investigação (Dasgupta, David, 1994, p.499), de tal forma que ser reconhecido como o primeiro a relatar corretamente um fato científico resulta de forma quase automática em vantagens acadêmicas - em um modelo em que "o vencedor leva tudo" (Strevens, 2003). Como vimos, essa busca por reconhecimento de prioridade associada à data de publicação torna especialmente relevante não apenas as datas em si, mas os contextos em que uma citação ocorre no artigo.

Em comentário publicado simultaneamente ao estudo de Persky e Brandt, Borody (2000) cita e reordena de modo cronológico os artigos de Eiseman, Bowden e as duas publicações de Schwan, e também recupera dois breves relatos de uso de TMF publicados em norueguês e outro em inglês - nenhum dos quais continha citações bibliográficas. Essa menção cronologicamente ordenada será encontrada em muitos trabalhos posteriores. $\mathrm{O}$ próprio grupo de Brandt viria a atribuir a prioridade da descoberta dos TMFs a Eiseman e colaboradores (1958) (Yoon, Brandt, 2010).

Desde então, na maioria dos artigos que se referem aos primeiros estudos do uso do TMF no tratamento da colite pseudomembranosa, a prioridade da descoberta é atribuída a Eiseman e colaboradores (1958). 


\section{Reconstruções da narrativa: outras alegações de prioridade}

As narrativas de Aroniadis e Brandt (2013) e de Van Nood et al. (2014) transcritas nas seções iniciais do presente trabalho estão organizadas em uma sequência cronológica que sugere que, na literatura acadêmica, surgiram primeiro referências ao uso do TMF na medicina tradicional chinesa, depois à transfaunação e por último ao consumo de fezes de camelos (e seus derivados). Entretanto, a apresentação dessa cronologia não obedece àquela dos trabalhos publicados, nos quais foram alegadas tais prioridades de descoberta. A proposição da precedência e, de certo modo, a alegação da prioridade da descoberta dos autores de todas as abordagens anteriores aos enemas de Eiseman se deu primeiro com a transfaunação, e depois entraram em cena o uso de fezes de camelo quase em simultâneo com a medicina tradicional chinesa.

De fato, é apenas em 2004 que Borody e colaboradores citam um artigo em alemão, de Klein e Müller, datado de 1941, sobre o tratamento de distúrbios gastrointestinais em ovinos. Naquele trabalho, Klein e Müller mencionam de forma breve o processo da transfaunação, que, segundo eles, havia sido descrito originalmente por Acquapendente em 1685. A transfaunação consistia na transferência de bolo alimentar já ruminado da boca de animal sadio para a boca de animal doente, curando-o. Embora Klein e Müller tenham mencionado a transfaunação como exemplo de tratamento no qual a relação causal entre a transferência de bactérias entéricas e a cura era desconhecida - afinal, tratava-se de uma publicação do século XVII -, Borody e colaboradores (2004) afirmam que "historicamente, o transplante de bactérias entéricas viáveis foi provavelmente descrito pela primeira vez pelo anatomista italiano Fabricius Aquapendente no século XVII". Vale notar que a transfaunação é significativamente distinta da ingestão de fezes mencionada por Bowden e colaboradores em 1981, uma vez que não há transferência oral de fezes, e sim de material ruminado. Essa imprecisão talvez se deva ao caráter informal das informações recebidas verbalmente por Bowden e seu grupo. A transfaunação voltaria, porém, a ser incluída em uma narrativa sobre os TMFs em artigo de revisão escrito por Johan Bakken em 2009. Bakken, no entanto, usa como fonte um livro-texto publicado em 2000, que não atribui a prioridade da descrição do procedimento a Acquapendente ou a qualquer outro autor. Bakken e Borody integrariam o conjunto de autores de uma nova revisão sobre os usos do TMF publicada em 2011, a qual faz referência à transfaunação mas cita o próprio Borody e colaboradores (2004) como fonte. Essa utilização de estudos empíricos ou artigos de revisão sobre os TMFs, como fontes de informação sobre a transfaunação, torna-se recorrente na literatura. Mas a prioridade da descoberta é quase sempre dada a Aquapendente por meio da menção explícita ao seu nome no texto (ver, por exemplo, Austin, Mellow, Tierney, 2014).

A provável condição prioritária de Aquapendente e sua transfaunação como precursores do transplante de bactérias entéricas também seria indiretamente posta em xeque por duas vezes e quase ao mesmo tempo em 2012. Em outubro daquele ano, Damman e colaboradores publicaram uma revisão sobre os TMFs como alternativas de tratamento para diversas doenças intestinais. Acrescentaram à narrativa sobre os TMFs o consumo de fezes de camelo para tratamento de disenteria por soldados alemães durante a Segunda Guerra Mundial: "Embora não seja normalmente praticada na espécie humana, a coprofagia foi 
observada entre beduínos do norte da África, que ingeriam esterco fresco de camelo como tratamento para disenteria. Essa prática foi observada pelos soldados alemães durante a Segunda Guerra Mundial e levou ao desenvolvimento de Bacillus subtilis para uso como probiótico" (Damman et al., 2012, p.1454).

Damman e colaboradores (2012) citam como fonte um artigo publicado por Ralph Lewin em 2001. Este, por sua vez, cita como fonte uma produção de Bernhardt cujo título em alemão pode ser traduzido como "Bacillus subtilis: isolamento e caracterização". A referência bibliográfica apresenta uma URL que, ao menos desde 2016, encontra-se inválida. A prática descrita por Lewin (2001) é posteriormente incorporada à narrativa sobre TMFs em diversos artigos, em especial nos de revisão. As fontes utilizadas como referências sobre o tema, porém, continuaram a ser sempre secundárias, mais comumente o artigo de Lewin (ver Van Nood, 2014).

Em novembro de 2012, Zhang e colaboradores (2012) publicaram, no prestigiado periódico The American Journal of Gastroenterology, uma carta-resposta a um artigo de Brandt e colaboradores (2012) na qual a transfaunação era mencionada como procedimento correlato dos TMFs. Em sua breve carta, Zhang e colaboradores descreveram duas abordagens da medicina tradicional chinesa por eles consideradas relacionadas ao TMF. A primeira, do século IV, prescrevia a ingestão de soluções fecais humanas no tratamento de envenenamentos ou diarreias graves. A segunda, do século XVI, propunha a ingestão de diversos tipos de soluções fecais humanas no tratamento de vários agravos, entre os quais Zhang e colaboradores incluíam a diarreia. A associação entre uso de soluções fecais como tratamento de diarreias e sua proximidade com os TMFs foi imediatamente reconhecida em resposta ao grupo, escrita pelo próprio Brandt (Brandt et al., 2012) e publicada na mesma edição da carta de Zhang.

O grupo de Brandt (Aroniadis, Brandt, 2013), bem como muitos outros autores (ver, por exemplo, Koenigsknecht, Young, 2013) rapidamente incluiriam aquelas práticas da medicina tradicional chinesa nas introduções de seus artigos sobre TMF. Assim, a prioridade da descoberta dos TMFs retrocedeu centenas de anos, deslocando-se para a China. Segundo Merton (1957, p.641), "em um mundo composto de estados nacionais, cada qual com sua porção de nacionalismo e etnocentrismo, as novas descobertas resultam em crédito não apenas para o descobridor como indivíduo, mas também para sua nacionalidade". Aqui é possível traçar um paralelo entre os cenários de produção científica mundial mencionados por Merton em 1957 e o cenário atual. Segundo Merton, “os russos que agora ocupam um espaço poderoso no cenário mundial insistem no caráter nacional da ciência e na importância de quem realizou determinada descoberta" (p.641). Isso contribuiria para "a recente propensão dos russos em reclamar a prioridade de todos os tipos sobre invenções e descobertas científicas, que reproduz ... a propensão de outras nações de reclamar tais prioridades" (p.642). Considerando a importância proeminente e crescente da China no cenário científico mundial a partir da década de 1980 (Zhou, Leydesdorff, 2006), é compreensível que cientistas e outros profissionais daquele país passassem a atribuir importância às alegações de prioridade de descoberta chinesas.

Entretanto, nossa hipótese é de que não houve continuidade entre o uso de TMF e as práticas da transfaunação, do uso de fezes de camelo por beduínos ou mesmo das práticas da 
medicina tradicional chinesa. As datas das primeiras menções aos relatos da transfaunação (2004), da medicina tradicional chinesa (2012) e do uso de fezes de camelo como recursos terapêuticos (2012) são tardias. Isso evidencia que esses processos eram desconhecidos de Eiseman em 1958 e de todos os autores dos relatos de casos, e assim como dos estudos clínicos sobre o uso de TMF publicados até 2004. Foi possivelmente a exploração cuidadosa da bibliografia por parte dos autores dos artigos de revisão na área biomédica que levou à localização dos relatos de transfaunação em 2004. A primeira referência em língua inglesa ao uso de fezes pelos beduínos foi publicada em 2001 em livro de divulgação científica sobre os diversos usos sociais das fezes humanas (Lewin, 2001). O fato de essa única fonte ser de certo modo externa à literatura acadêmica deve ter contribuído para a demora em sua inclusão na narrativa (ocorrida apenas em 2012). Já o crescente reconhecimento da importância clínica dos TMFs possivelmente motivou os autores chineses a reivindicar a prioridade de descoberta para a medicina tradicional chinesa também em 2012.

A narrativa, portanto, foi reconstruída de forma gradativa em artigos de revisão graças a achados posteriores aos estudos clínicos e a relatos de caso propriamente ditos, sendo depois incorporada, no todo ou em parte, às seções introdutórias de artigos de revisão e de estudos clínicos.

Em 2015, porém, o próprio The American Journal of Gastroenterology publicou nova carta aos editores: "Uma evidência enganosa de transplante de microbiota fecal" (Jia, 2015). Naquela carta, Jia contestava qualquer similaridade entre as práticas tradicionais chinesas e os TMFs, argumentando que as soluções fecais teriam sido utilizadas na tradição chinesa em situações de envenenamento, essencialmente com a intenção de induzir o vômito e a eliminação do veneno. Em sua resposta a Jia, Zhang e Zhu (2015) defenderam a proposição original. O alcance da crítica de Jia, porém, contrasta com o da reivindicação da prioridade de Zhang: a carta original de 2012 recebeu mais de cem citações até novembro de 2018, enquanto sua contestação por Jia recebeu apenas duas, nenhuma delas relacionada à controvérsia com Zhang.

A aceitação quase imediata das alegações de prioridade descritas nesta seção contrasta com o longo prazo decorrido até o reconhecimento da prioridade de descoberta de Eiseman e colaboradores (1958). É possível especular que o reconhecimento de prioridades de autores muito distantes no tempo e externos à comunidade acadêmica seja mais simples, pois não afeta diretamente o sistema de recompensas intrínseco à atividade científica atual. Essa hipótese não esgota as possibilidades de explicação para essas diferenças. Por exemplo, o contraste entre a aparente relutância da comunidade biomédica em reconhecer a prioridade de Eiseman e a rápida aceitação da prioridade da medicina tradicional chinesa sugere que pode ter sido mais aceitável para aquela comunidade reconhecer a prioridade de autores relacionados a um registro temporal e epistemológico distinto do que a de um outro cientista contemporâneo.

Em conjunto, esses achados indicam que a construção da narrativa atual sobre as prioridades no uso de TMFs consolidou-se por volta de 2013. Em sua versão mais completa, ela se inicia na China, nos séculos IV e XVI, é retomada primeiro na Itália, no século XVII, e em seguida na década de 1940, sendo finalmente concluída com a referência ao trabalho do grupo de Eiseman de 1958. 


\section{O transplante de microbiota fecal como um fato científico}

Pode-se sugerir uma hipótese explicativa adicional para a demora em reconhecer a prioridade de Eiseman e colaboradores: os médicos e cientistas de princípios da década de 1980 não possuíam um aparato conceitual para compreender o alcance daquele breve relato publicado em 1958. No entanto, ao contrário disso, o que se percebe é que embora não citem Eiseman e colaboradores, os autores da década de 1980 se apoiam em uma lógica muito similar, o que parece indicar o estabelecimento de um estilo de pensamento do qual o próprio Eiseman fez parte: a ideia da recolonização do trato gastrointestinal pela microbiota presente nas fezes de indivíduos sãos. Apoiados no conceito de estilo de pensamento de Ludwik Fleck (2010), argumentamos que o estilo de pensamento implicado pelos TMFs era diferente do estilo hegemônico da década de 1950, que preconizava o uso de antibióticos para enfrentar doenças infecciosas, caso da colite pseudomembranosa.

A colite pseudomembranosa é conhecida há mais de um século, mas a identificação do Clostridium difficile como seu agente etiológico foi publicada por Bartlett e colaboradores somente em 1977. A inexistência de um agente etiológico definido para a colite pseudomembranosa tornava mais difícil propor uma terapia definida para aquela patologia. A identificação inequívoca do Clostridium difficile como agente etiológico suscitou o desenvolvimento de testes para sua identificação e de suas toxinas nas fezes. Disso adveio a possibilidade de aferição da eficácia dos diversos tratamentos - incluídos os alternativos, como os TMFs.

A intensificação do uso dos TMFs como medida extrema a partir da década de 2000 deveu-se certamente ao aparecimento e disseminação de linhagens de Clostridium difficile resistentes aos antibióticos utilizados no tratamento da colite pseudomembranosa, associados ao surgimento de cepas extremamente virulentas do patógeno com graves implicações para a saúde pública (Bartlett, 2006). Mas também é resultado do desenvolvimento de uma forma diferente de compreender a relação entre paciente e doença, entre hospedeiros e parasitas.

Para Anderson (2004, p.40), os historiadores, até meados da década de 1960, assim como a maioria dos cientistas e médicos que estudavam a medicina, teriam escolhido enfatizar "o desenvolvimento, durante o século XX, de modelos laboratoriais simplificados para mecanismos fisiopatológicos complexos". Além disso, o diagnóstico e prevenção de doenças teriam sido "comumente enquadrados em termos de 'caça aos micróbios' e tratamento em termos de 'balas mágicas'” (p.40). Tais conceitos faziam parte de um estilo de pensamento conhecido como otimismo sanitário, em vigor nas duas primeiras décadas após a Segunda Guerra Mundial (Farley, 2004; Garret, 1995). Esse otimismo sanitário era composto por três eixos principais: o uso de DDT para o controle de vetores de doenças, a aplicação massiva de vacinas para imunizar populações e a prescrição de antibióticos para cura e controle de infecções (Farley, 2004; Garret, 1995). Dessa perspectiva mais ampla, o trabalho de Eiseman poderia ser interpretado como uma abordagem focada em um estilo de pensamento distinto ao do otimismo sanitário:

Uma aumentada confiança no desenvolvimento de antibióticos e vacinas durante a década de 1960 e a década de 1970, no entanto, levou à negligência de tais interpretações ecológicas de doenças infecciosas. Na década de 1980, a natureza revidou. Doenças 
emergentes, como a Aids, e problemas relacionados à resistência microbiana aos antibióticos, levou a um reexame generalizado de nossa coabitação com os micróbios. 'Era hora', Lederberg escreveu no ano 2000, 'de abandonar a velha metáfora de uma guerra entre germes e humanos, substituindo-a por uma metáfora mais ecologicamente informada, que inclui o ponto de vista do agente infeccioso'. Acima de tudo, ele concluiu, precisamos de mais 'pesquisas sobre a ecologia microbiana de nossos próprios corpos' (Anderson, 2004, p.40).

Entretanto, segundo Anderson, existiam abordagens ecológicas na medicina pelo menos desde meados da década de 1930. Assim, o trabalho de Eiseman e colaboradores foi publicado em uma época em que um estilo de pensamento ecológico para questões médicas, embora não predominante entre os médicos, já tinha sido desenvolvido por alguns personagens como Theobald Smith, F. Macfarlane Bumet, René Dubos e Frank Fenner (Anderson, 2004). Nesse âmbito, além de ter sido uma resposta inovadora e bem-sucedida a um grave problema de saúde, o uso do enema proposto por Eiseman configuraria parte de um movimento que só começou a ser mais visível quase três décadas mais tarde, quando a ecologia passou a ser reconhecida por médicos, agências de pesquisa e instituições como uma ciência imprescindível no equacionamento de certos problemas de saúde (Anderson, 2004). Dessa perspectiva, portanto, não apenas o trabalho de Eiseman, mas outras abordagens de cunho mais ecológico, como o uso de probióticos e mesmo de linhagens não toxigênicas de Clostridium difficile (Seal et al., 1987), podem ser interpretados como participantes de um estilo de pensamento diferente daquele dos caçadores de micróbios ou das balas mágicas.

Podemos concluir propondo um entrelaçamento das duas linhas de análise exploradas no presente texto: a das alegações de prioridade sobre o uso dos transplantes de microbiota fecal e a da mudança de estilo de pensamento. O período decorrido entre a publicação do trabalho de Eiseman e colaboradores (1958) e a primeira citação a ele, no contexto dos transplantes de microbiota, em princípios da década de 1990 (Borriello, 1990), resultaria de dois fatores complementares. Um deles seria as diferenças entre os conceitos ecológicos subjacentes ao uso do TMF e os conceitos subjacentes ao uso de antibióticos para debelar doenças. Embora os primeiros relatos de usos clínicos dos transplantes de microbiota fecal não tenham reconhecido a prioridade de Eiseman e colaboradores (1958), eles se deram no âmbito de um estilo de pensamento que começava a levar em consideração conceitos ecológicos que se contrapõem ao estilo de pensamento associado às ideias de caçadores de micróbios e balas mágicas (os antibióticos). De maneira concomitante, há uma sutil disputa na atribuição de prioridades da descoberta do TMF até a década de 1990. Ela pode ser interpretada como uma demora, intencional ou não, em reconhecer no trabalho de Eiseman e colaboradores o estilo de pensamento que estava começando a se apresentar como algo distinto do modelo das balas mágicas.

A explosão epidêmica da colite pseudomembranosa, refratária ao uso de antibióticos a partir de 2000, contribuiu para avaliações mais criteriosas dos transplantes de microbiota fecal. Talvez pressionados pela ineficácia das formas de tratamento mais convencionais em diversos casos, os atores em questão tenham sido tentados a explorar outras maneiras, em particular os TMFs. Embora o estilo de pensamento empregado por Eiseman e seu grupo em 1958 não tenha recebido as recompensas derivadas da prioridade da descoberta, ele 
tem sido cada vez mais mobilizado diante das limitações das formas tradicionais de lidar com a colite pseudomembranosa.

Já os extensos lapsos de tempo decorridos entre os demais elementos que passam a compor a narrativa a partir da década de 2000 (transfaunação, medicina tradicional chinesa e consumo de fezes de camelo) podem ser, ao menos em parte, explicados por esforços para atribuição retroativa de prioridades a estudos relacionados aos TMFs.

\section{NOTAS}

${ }^{1} \mathrm{O}$ enema fecal é uma adaptação de uma técnica rotineira, o enema de retenção, que consiste na inserção de fluídos no reto, por meio de equipamentos apropriados, de modo que os fluidos possam permanecer por períodos relativamente longos e ser absorvidos pelo cólon. No enema fecal, os fluidos terapêuticos eram substituídos por uma solução diluída de fezes. Ao longo das últimas décadas, variações do enema fecal foram testadas com o mesmo objetivo: sondas nasogástricas e colonoscopias (Brandt et al., 2012). No corpo do texto, porém, adotaremos a terminologia atual brasileira: transplante de microbiota fecal (TMF) (Ganc et al., 2015).

${ }^{2}$ As citações foram identificadas por meio de cruzamento dos registros recuperados nas ferramentas Europe "Colite Pseudomembranosa" (<https://europeCOLITEPSEUDOMEMBRANOSA.org/>) e Pubmed. Os termos de busca utilizados foram aqueles definidos por Gough, Shaikh e Manges (2011) em sua revisão sistemática recente.

\section{REFERÊNCIAS}

ANDERSON, Warwick.

Natural histories of infectious disease: ecological vision in twentieth-century biomedical sciences. Osiris, v.19, p.39-61. 2004.

ARONIADIS, Olga C.; BRANDT, Lawrence J. Fecal microbiota transplantation: past, present and future. Current Opinion in Gastroenterology, v.29, p.79-84. 2013.

AUSTIN, Matthew; MELLOW, Mark; TIERNEY, William M.

Fecal microbiota transplantation in the treatment of Clostridium difficile infections. The American Journal of Medicine, v.127, n.6, p.479-483. 2014.

BAKKEN, Johan.

Fecal bacteriotherapy for recurrent Clostridium difficile infection. Anaerobe, v.15, p.285-289. 2009.

BARTLETT, John G.

Narrative review: The new epidemic of

Clostridium difficile-associated enteric disease. Annals of Internal Medicine, v.145, n.10, p.758764. 2006.

BARTLETT, John G.

Antibiotic-associated pseudomembranous colitis. Reviews of Infectious Diseases, v.1, p.530539. 1979.
BARTLETT, John G. et al.

Clindamycin-associated colitis due to a toxinproducing species of Clostridium in hamsters. The Journal of Infectious Diseases, v.136, n.5, p.701-705. 1977.

BOJANOVA, Diana P.; BORDENSTEIN, Seth R. Fecal transplants: what is being transferred? Plos Biology, v.14, n.7, e1002503. 2016.

BORODY, Thomas J.

'Flora power': fecal bacteria cure chronic C.difficile diarrhea. The American Journal of Gastroenterology, v.95, n.11, p.3028-3029. 2000.

BORODY, Thomas J. et al.

Bacteriotherapy using fecal flora toying with human motions. The Journal of Clinical Gastroenterology, v.38, n.6, p.475-483. 2004.

BORRIELLO, Peter S.

The influence of the normal flora on Clostridium difficile colonisation of the gut. Annals of Medicine, v.22, p.61-67. 1990.

BOWDEN, Talmadge A; MANSBERGER, Arlie R.; LYKINS, Lawrence E.

Pseudomembranous enterocolitis: mechanism of restoring floral homeostasis. The American Surgeon, v.47, p.178-183. 1981.

BRANDT, Lawrence J. et al.

Response to Zhang et al. American Journal of Gastroenterology, v.107, n.11, p.1755-1756. 2012. 
CONDÉ, Mauro Lúcio Leite.

Mutações no estilo de pensamento: Ludwik Fleck e o modelo biológico na historiografia da ciência. Revista de Filosofia Moderna e Contemporânea, v.6, n.1, p.155-186. 2018.

CURTIS, Valerie; BIRAN, Adam.

Dirt, disgust, and disease: is hygiene in our genes? Perspectives in Biology and Medicine, v.44, n.1, p.17-31. 2001.

DAMMAN, Christopher J. et al.

The microbiome and inflammatory bowel disease: is there a therapeutic role for fecal microbiota transplantation? American Journal of Gastroenterology, v.107, p.1452-1459. 2012.

DASGUPTA, Partha; DAVID, Paul A.

Toward a new economics of science. Research Policy, v.23, p.487-552. 1994.

EISEMAN, Ben et al.

Fecal enema as an adjunct in the treatment of pseudomembranous enterocolitis. Surgery, v.44, p.854-858. 1958.

FARLEY, John.

To cast out disease: a history of the International Health Division of the Rockefeller Foundation (1913-1951). New York: Oxford University Press. 2004.

FINEGOLD, Sydney M.; GEORGE, Lance W. Therapy directed against Clostridium difficile and its toxins: complications of therapy. In: Rolfe, Rial D.; Finegold, Sidney M. Clostridium difficile: its role in intestinal disease. San Diego: Academic Press. p.342-366. 1988.

FLECK, Ludwik.

Gênese e desenvolvimento de um fato científico. Belo Horizonte: Fabrefactum. 2010.

FULLER, Roy.

Probiotics in human medicine. Gut, v.32, p.439442. 1991.

GALDYS, Alison L.; CURRY, Scott R.; HARRISON, Lee $\mathrm{H}$.

Asymptomatic Clostridium difficile colonization as a reservoir for Clostridium difficile infection. Expert Review of Anti-infective Therapy, v.12, n.8, p.967-980. 2014.

GANC, Arnaldo J. et al.

Transplante de microbiota fecal por enteroscopia alta para o tratamento da diarreia causada por Clostridium difficile. Einstein, v.13, n.2, p.338339. 2015.

GARRET, Laurie.

A próxima peste: novas doenças num mundo desconhecido. Rio de Janeiro: Nova Fronteira. 1995.
GHOSE, Chandrabali.

Clostridium difficile infection in the twentyfirst century. Emerging Microbes and Infections, v.2, n.62. 2013.

GORE, Richard M. et al. Infectious colitis. In: Levy, Angela D. et al. Gastrointestinal imaging. Oxford: Oxford University Press. p.236-242. 2015.

GOUGH, Ethan; SHAIKH, Henna; MANGES, Amee R.

Systematic review of intestinal microbiota transplantation (fecal bacteriotherapy) for recurrent Clostridium difficile infection. Clinical Infectious Diseases, v.53, n.10, p.994-1002. 2011.

JIA, N.

A misleading reference for fecal microbiota transplant. The American Journal of Gastroenterology, v.110, n.12, p.1731. 2015.

KOENIGSKNECHT, Mark J.; YOUNG, Vincent B. Fecal microbial transplantation for the treatment of Clostridium difficile infection: current promise and future needs. Current Opinion of Gastroenterology, v.29, n.6, p.628-632. 2013.

LEWIN, Ralph A.

More on merde. Perspectives in Biology and Medicine, v.44, n.4, p.594-607. 2001.

LEY, Ruth E; PETERSON, Daniel A; GORDON, Jeffrey I.

Ecological and evolutionary forces shaping microbial diversity in the human intestine. Cell, v.124, p.837-848. 2006.

MERTON, Robert K.

The Matthew effect in science, II: cumulative advantage and the symbolism of intelectual property. Isis, v.79, p.606-623. 1988.

MERTON, Robert K.

A ciência e a estrutura social democrática. In: Merton, Robert K. Sociologia: teoria e estrutura. São Paulo: Mestre Jou. p.651-662. 1970.

MERTON, Robert, K.

Priorities in scientific discover: a chapter in the sociology of science. American Sociological Review, v.22, n.6, p.635-659. 1957.

PERSKY, Seth E.; BRANDT, Lawrence J. Treatment of recurrent Clostridium difficileassociated diarrhea by administration of donated stool directly through a colonoscope. The American Journal of Gastroenterology, v.95, n.11, p.3283-3285. 2000.

ROFFE, Christine.

Biotherapy for antibiotic-associated and other diarrhoeas. Journal of Infection, v.32, p.1-10. 1996. 
ROLFE, Rial D.; FINEGOLD, Sidney M. Clostridium difficile: its role in intestinal disease. Academic Press: San Diego. p.183-200. 1988.

RUPNIK, Maja; WILCOX, Mark H.; GERDING, Dale N.

Clostridium difficile infection: new developments in epidemiology and pathogenesis. Nature Review Microbiology, v.7, p.526-538. 2009.

SCHWAN, Anna et al.

Relapsing Clostridium difficile enterocolitis cured by rectal infusion of normal faeces. Scandinavian Journal of Infectious Diseases, v.16, p.211-215. 1984.

SCHWAN, Anna et al.

Relapsing Clostridium difficile enterocolitis cured by rectal infusion of homologous faeces. The Lancet, v.8, p.845. 1983.

SEAL, Douglas et al.

Treatment of relapsing Clostridium difficile diarrhoea by administration of a non-toxigenic strain. European Society of Clinical Microbiology, v.6, n.1, p.51-53. 1987.

STREVENS, Michael.

The role of the priority rule in science. The Journal of Philosophy, v.100, n.2, p.55-79. 2003.

TVEDE, Michael; RASK-MADSEN, Jorgen. Bacteriotherapy for chronic relapsing Clostridium difficile diarrhoea in six patients. Lancet, v.1, n.8648, p.156-160. 1989.

VAN NOOD, Els et al.

Fecal microbiota transplantation: facts and controversies. Current Opinion in Gastroenterology, v.30, p.34-39. 2014.
VAN NOOD, Els et al.

Duodenal infusion of donor feces for recurrent Clostridium difficile. The New England Journal of Medicine, v.368, p.407-415. 2013.

WHITMAN, William B.; COLEMAN, David C.; WIEBE, William J.

Prokaryotes: the unseen majority. Proceedings of the National Academy of Sciences, v.95, p.65786583. 1998

WILSON, Kenneth H.

Microbial ecology of Clostridium difficile. In: Rolfe, Rial D.; Finegold, Sidney M. Clostridium difficile: its role in intestinal disease. San Diego: Academic Press. p.183-200. 1988.

WILSON, Kenneth H.; SILVA, Joseph; FEKET, F. Robert.

Suppression of Clostridium difficile by normal hamster cecal flora and prevention of antibioticassociated cecitis. Infection and Immunity, v.34, n.2, p.626-628. 1981.

YOON, Sonia S.; BRANDT, Lawrence J.

Treatment of refractory/recurrent C. difficileassociated disease by donated stool transplanted via colonoscopy: a case series of 12 patients. Clinical Gastroenterology, v.44, p.562-566. 2010.

ZHANG, Faming et al.

Should we standardize the 1,700-year-old fecal microbiota transplantation? The American Journal of Gastroenterology, v.107, n.11, p.1755. 2012.

ZHANG, Faming; ZHU, Heming.

Reply to Jia. The American Journal of

Gastroenterology, v.110, n.12, p.1731-1732. 2015.

ZHOU, Ping; LEYDESDORFF, Loet.

The emergence of China as a leading nation in science. Research Policy, v.35, p.83-104. 2006. 